as being sufficient to prevent any outbreak of small-pox assuming serious epidemic proportions. Now, what did Dr. Coupland find at Gloucester? That a few slight or mild cases in 1895 were followed by a severe epidemic extending from February to April 1896, in which not only was there an increase in the numbers attacked, but there $\mathrm{w} \mathrm{s}$ also an undue proportion of cases of a severe type accompanied by a high rate of mortality. As showing how in a community with a large proportion of unvaccinated children the disease may spread rapidly, we have the fact that there was an "almost simultaneous invasion of many homes through children who were infected whilst attending certain of the public elementary schools." As a result of this sudden outbreak it became impossible to provide hospital accommodation, and, ultimately, all attempts at isolation, of even a modified form, had to be abandoned as utterly impracticable. As a result of the crowding of the hospitals, and of the removal of the most severe cases to them, the hospital mortality was comparatively high, and the friends of the patients would soon not permit of the removal of these patients to hospitals; this, of course, resulting in an utter break-down of the system of isolation.

Dr. Coupland sums up in the following exceedingly striking passages. He says: "There is no escape from the conclusion that the heightened mortality and the severity of the epidemic were greatly due to so large a proportion of unvaccinated children being attacked; for (a) the case mortality under ten years of age was $39^{\circ} 6$ per cent., whilst amongst the vaccinated it was only $3^{\circ} 9$ per cent., leaving a mortality amongst the unvaccinated of $4 \mathrm{I}$ per cent. . . . (b) The disparity is quite as marked when the type of the attack is contrasted, for of 507 cases of severe attacks [malignant, confluent, indeterminate] there actually occur only three amongst the vaccinated." From these and other considerations it follows that in the Gloucester epidemic "the severity of the disease, its high mortality, and its propagation were influenced and promoted by the unduly large proportion of unvaccinated children who were exposed to infection and who were infected."

To whatever figures or tables we turn, the effect of them is always the same. They tell the same story - vaccination protects; unvaccinated children are left susceptible to the attacks of the disease, and they not only take the disease more readily, but they take it in a more dangerous and fatal form, and, in most cases at any rate, are a source of greater danger to those with whom they may come, directly or indirectly, in contact. Isolation, good hospital accommodation, and favourable sanitary conditions are useful in the treatment of smallpox in a vaccinated community; but once let small-pox find its way into an unvaccinated community, the inefficiency of these "accessory" measures, when used alone, are demonstrated with the most absolute clearness; and if Gloucester has one lesson more than another to teach, it is that Jenner, by his advocacy of vaccination, did more to limit the spread of small-pox than have all the sanitarians of the century. Small-pox undoubtedly does not come under the class of diseases that can be held in check by ordinary sanitary measures; these, no doubt, are contributory, but without vaccination they can never be depended upon as being fully effective.

\section{CANADIAN GEOGRAPHY.}

THE reissue of "Stanford's Compendium" now includes Australia and the Pacific Islands in two volumes by separate authors, Asia in two volumes and NO. I 47 I, VOL. 57$]$
Africa in two volumes by the same author, and vol. i. of North America. ${ }^{1}$ The new issue is in many ways vastly superior to the old; the cramping influence of the foreign original has disappeared, the illustrations have greatly improved, and, linked by the general title, each of the volumes forms a separate and original work of distinct value. So good, indeed, has "Stanford's Compendium " become, that it may now be allowable to subject one of its volumes to criticism of a more searching kind than would have been justified formerly. Then any attempt to form a library of solid geographical works in the English language was worthy of commendation; now it is possible to set up a higher standard, and it is reasonable to look for those excellencies of grasp and arrangement which one naturally expects in, let us say, a German work of similar scope.

The morphological unity of the continent is one of the fundamental facts of modern geography. The continent is the natural unit which must be considered in its entirety, with parts subordinated to the whole, and with functional activities of a distinctive kind. It is capable of subdivision, either naturally into regions or artificially into countries, and of aggregation with other continents to form the whole land-surface. The dominant lines of the continent-its axial mountain systems-determine
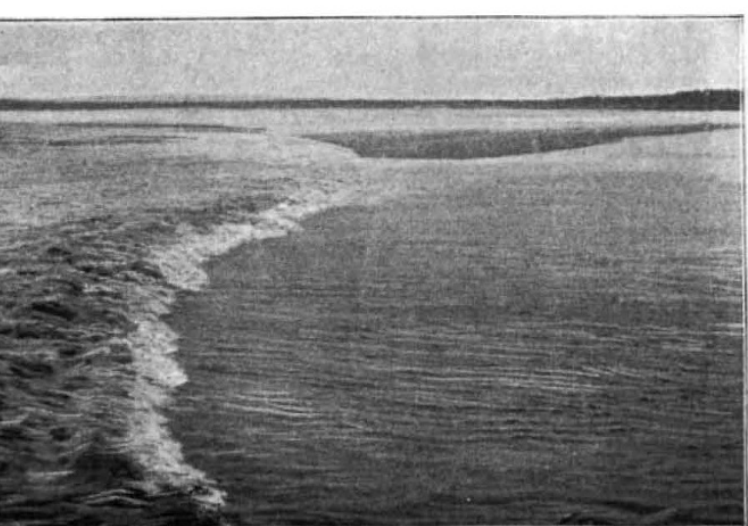

IG. I. - The Bore, Petitcodiak River, Moncton, New Brunswick, August 8, 1892. Height, 5 feet 4 inches.

the primitive slopes of the land, and the development of the river systems, subject to the continuous workings of secular uplift or depression and the accumulation of sediment. The resulting configuration modifies the climate as dependent on latitude, and leads to the formation of areas of moderate and of extreme temperature, of high rainfall and of aridity. Climate reacts on vegetation, and vegetation and climate together influence the distribution of animals; and all these varieties of feature and function are framed in the continent. Thus up to the appearance of man a geographical description must be based on the continent as a unit if it is to be really simple and comprehensible. With the advent of man complications arise, but the guiding influence of the main features of continental relief and surface-covering is still to be traced. The deep inlets tempt the adventurous stranger to penetrate the continent, the easy waterways lure him into the interior, where products of forest and plain supply an adequate inducement to remain or to return. In time groups of people settle down in habitats more or less distinctly defined by natural featuresdifferent tribes frequent the river, the lake, the forest, the plain, the mountain valley, the indented ocean shore.

I "Stanford"s Compendium of Geography and Travel" (new issue). Maps and illustrations. (London: Edward Stanford, r897.) 
Consequent pressure of population or change in the availability of resources sets up migratory movements along natural lines dictated by land-form, water-flow, and soilcovering; conquest and delimitation ensue, and the straight boundary lines of the map, which come last, are, after all, natural relations to geographical facts associated with the whole body of the earth itself and its rotation. The grouping of dwelling-places around certain centres leading to the origin of towns may also, as a rule, be explained by geographical considerations.

Of the six continents which are usually recognised two stand out from the rest, distinguished by the simplicity of their great features and the clearness of the interdependence of the various relationships. These are North and South America, either of which forms an ideal subject for a geographical monograph.

We have mentioned the superiority of the new issue of "Stanford's Compendium" over the old ; but there is one point of distinct inferiority. The old issue retained some traces of the original design, giving it a certain unity; the new is not so much a compendium as a series of ing of the provinces of the Dominion. Unexpected comparisons and contrasts of the aptest kind with the course of history in other lands and other times continually delight the reader's mind and illuminate the story. But when from history the author enters geography the wheels seem to drop from his chariot, and he drives heavily. One could imagine that he wrote with effort, perhaps even with distaste. His comparisons lose point, and are sometimes inaccurate. Canada is not, as stated on p. 29 , "above all others the land of abundance of waters.". Finland or Sweden would, we believe. correspond better-certainly as well-to the definition, If any great river is to be celebrated for the length of its tributaries it should surely be the Amazon, the Congo, the Mississippi, rather than the St. Lawrence (p. 34). As to climate, we dispute the suggestion that tobacco cannot be grown in England (p. 47), and we must remember the success of Lord Bute's wine-making from grapes grown in the open air at Cardiff. The treatment of climate is otherwise not fully satisfactory. While no attempt is made to deny that the Canadian winter is

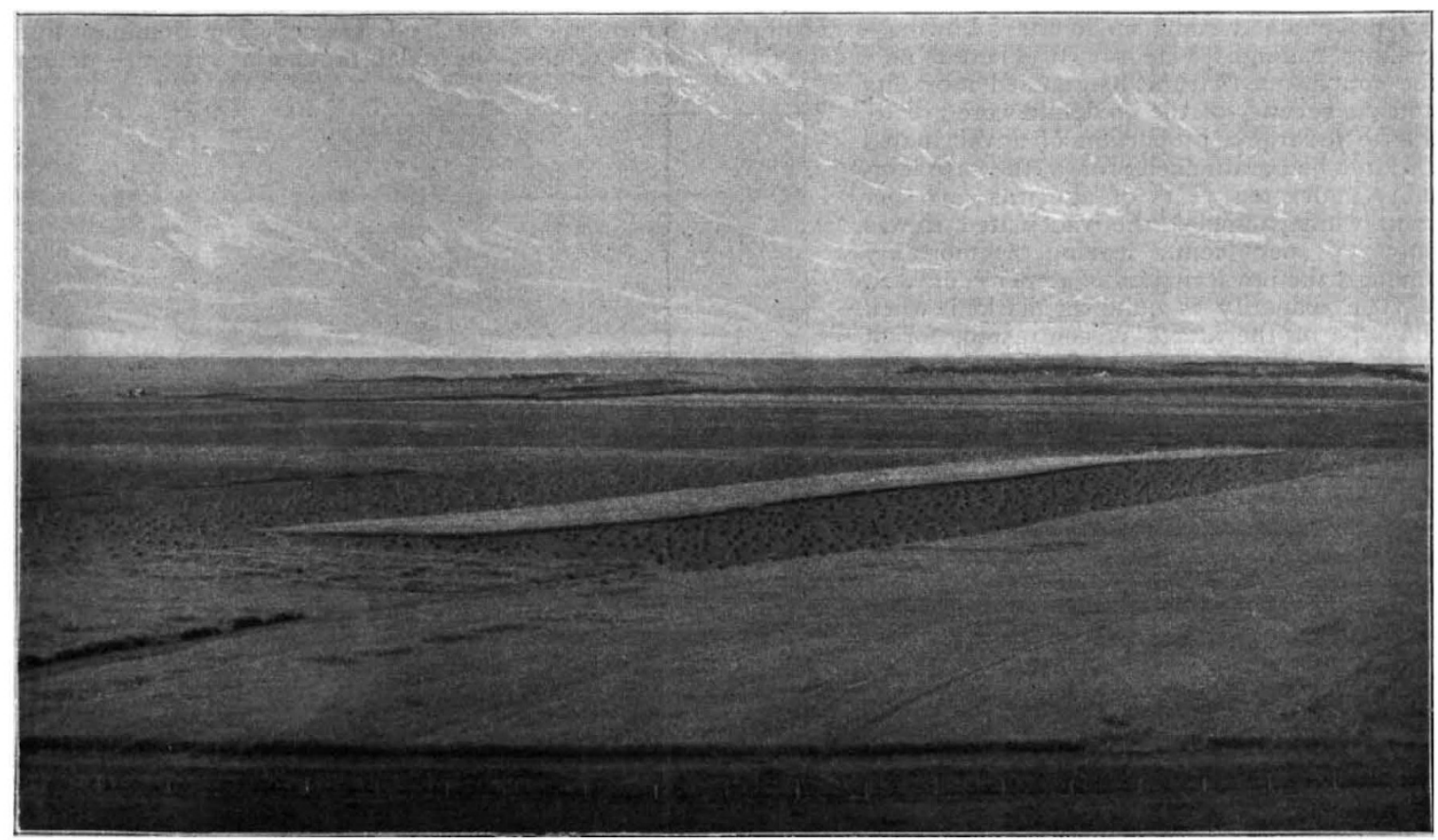

FIG. 2.-The Prairie, Manitoba.

separate works. Dr. S. E. Dawson's “North America, Vol. i." is not, strictly speaking, the first part of a geographical description of North America. It is the description of the Dominion of Canada and Newfoundland, written not from the standpoint of a geographer, but from that of an imperialist British subject and patriotic Canadian. The author infuses warm colour into his narrative, which, gratifying as it must be to the sentiments of the people of the British Empire, does not enhance the value of the work as a scientific treatise. Dr. S. E. Dawson is obviously not himself a geographer - his strength lies in his treatment of history. Having expressed our view as to what a geographical treatise on a continent should be, we need only add that "North America, Vol. i.," is written without regard to the guiding principles of geographical science.

We have seldom, if ever, read more satisfying or more graceful renderings of history than the chapters of this book dealing with the discovery, exploration and occupy- cold, the author seems more concerned to combat what he believes to be the average Englishman's exaggerated ideas on the subject than to describe the actual conditions. With regard to the French of Quebec (p. 295), which some people seem to have called a patois, the author observes: "English is not spoken in the same way over all the United Kingdom, but no one speaks of a Dublin or an Aberdeen patois, or for that matter of a London patois." We can assure him that some people do speak of the dialect (a word as displeasing as patois) of these parts, and many authors, with an eye to popularity, delight to exaggerate rather than minimise such differences. The tunnel at Sarnia, 6025 feet long (p. 391), cannot be termed "one of the greatest in the world," unless the standard of greatness is put very low, and the number of great tunnels made very large.

These are instances which do not seriously detract from the value of the book to the general reader; but Canada is so great, and its natural resources are so vast, 
that comparisons of the kind would be quite unnecessary even if they were sound. A somewhat serious defect is the occasional imperfect revision, giving rise in the nonhistorical sections to repetition and to vague or even inaccurate phrases, such as the description of a boundary as a "perpendicular line" (p. 453) when a meridian is meant. We note a few omissions: nothing appears to be said of the extreme danger of the Magdalen Islands, in the Gulf of St. Lawrence, to shipping; of the devastation of the forests in many parts of the country by fire; or of the high " benches" or river-terraces of British Columbia, which to a geographer form, perhaps, the most striking feature of that wonderful province.

We must, however, make it perfectly distinct that so far as the matter in this book is concerned the omissions are trifling, and the selection of facts most judicious. Dr. S. E. Dawson handles themes regarding which a Canadian might justly be excused if he were to indulge in a little exaggeration; and if the writer of this notice had never seen Canada, he would have supposed that there was some exaggeration here. But a journey from Quebec to Nanaimo, with visits to various points in the Kootenay and on the shores of the Great Lakes, has convinced the critic that in every estimate of natural wealth, and in every appreciation of the law-abiding enterprise of the Canadian people, the author has under-stated rather than overstated the facts. If a passing tourist of no very imperial. istic tendencies felt the pride of a citizen of the British Empire rising within him with each mile of the magnificent railway which is the benefactor of every province in the Dominion, he cannot but be surprised at the moderation of tone adopted by an heir of that fair heritage in writing an account of its actual and potential greatness.

Yet the book is not planned in harmony with the principles of geography, and that, after all, is the aspect to which attention must be called in the pages of a scientific journal. The illustrations are good, and characteristic, as the specimens here reproduced show, and the maps very fair, although not so numerous or so well selected as we could wish. There are practically no physical maps, for the sketch of the Archæean nucleus on p. 24 is a mere diagram, and the "Meteorological Map" shows only mean annual isotherms, which give no clue to the climate, and rainfall areas, which are difficult to grasp as a whole. There is certainly no lack of cartographic material in Ottawa, as the beautiful physical maps in the "Handbook of Canada," issued in connection with the recent meeting of the British Association, prove.

HUGH ROBERT MILL.

THOMAS JEFFERY PARKER, F.R.S.

THOMAS JEFFERY PARKER, whose death on

November 7 last we chronicled on December 23 , was the eldest son of the late William Kitchen Parker, F.R.S., the world-renowned comparative osteologist. $\mathrm{He}$ was born at 124 Tachbrook Street, London, S.W., on October 17,1850 , and received his elementary education at Clarendon House School in the Kennington Road, under Dr. C. H. Pinches. In 1868 he entered the Roya: School of Mines as a student, taking the Associateship in Geology in 187I, together with the Edward Forbes medal and prize of books for distinction in biology. Thus qualified, he became for a short period science master at Bramham College, Yorkshire; but in 1872 , on a special invitation by Huxley, he returned to London to fill the office of demonstrator under him at South Kensington, and that he held until his appointment in 1880 to the chair of Biology in the University of Otago, Dunedin, N.Z. During his period of demonstratorship he also held the office of Lecturer in Biology in Bedford College, London, and officiated as examiner in Zoology and Botany to the University of Aberdeen and as an assistant examiner in Physiology to the Science and Art Department. Parker was of a distinctly artistic temperament, æsthetic, musical, well-read, and possessed of marked literary ability, which asserted itself to a conspicuous degree in his little book upon his father, published in 1893 , an altogether ideal filial biography-a good work by a good man. He early cultivated the critical faculty, as a direct result of the study of Matthew Arnold, whose writings he knew by heart; and with the great power of application and strength of character which he displayed during active work, there can be little doubt that he would have succeeded in any of the higher walks of life. He would have made a mark in literature, and as a caricaturist draughtsman would have achieved renown; and there is little doubt that his choice of biology for his life's calling was largely due to the charm and influence of his father's career and to his early association with Huxley, who knew him from childhood and became the object of his veneration. Both as a teacher and investigator Parker was untiring and thoroughly trustworthy. Though easily roused to enthusiasm he rarely became excited, and his cool deliberation came welcomely to the aid of the troubled student, to whom if in earnest his attention knew no bounds. His published papers exceed forty in number, and though mostly zoological they embody important work and observations in botany. Parker was the first appointed of the little band of biological professors sent out from home in the '8o's, who now fill the Australian and Novozelandian chairs, and his second paper published in New Zealand dealt with a new species of Holothurian (Chirodota Dunediensis), as it were in anticipation of the later determination by himself and his contemporaries at the Antipodes to devote their attention to the indigenous fauna, rather than to refinements in histology and the like which could be better studied at home. The work already achieved by this body of investigators, with Parker at their head, is now monumental, and none of it more so than Parker's monographs "On the Structure and Development of Apteryx" and "On the Cranial Osteology, Classification, and Phylogeny of the Dinornithidæ," in themselves sufficient to have established his reputation. His lesser writings, although they deal with a wide range of subjects, show interesting signs of continuity of ideas, as for example in the association of his early observations on the stridulating organ of Palinurus, made in London in 1878 , with those upon the structure of the head in certain species of the genus (one of the most charning of his shorter papers), made on the voyage to New Zealand, and upon the myology of P. Edrvardsii, which, in co-operation with his pupil Miss Josephine Gordon Rich (now Mrs. W. A. Haswell), he in I 893 contributed to the Macleay Memorial volume. And the same may be said of his work on the blood-vascular system of the Plagiostomi. Soon after his arrival at the Antipodes, Parker instituted a series of "Studies in Biology for New Zealand Students," and chiefly with the aid of his pupils, these have been continued, either in their original form or in that of theses for the higher degrees of the University of New Zealand, a. contributions to the publications of the Museum and Geological Survey Department of that colony. Botanical as well as zoological topics were thus taken in hand, the series, like that of a companion set of "Notes from the Otago University Museum," which he from time to time contributed to the pages of NATURE, containing important observations of general biological interest. Of Parker's books, it is sufficient to recall his "Lessons in Elementary Biology," now in its third edition and recently translated into German, undoubtedly the most important and trustworthy work for the elementary student which has appeared since Huxley and Martin's epoch-marking. "Practical Instruction in Elementary Biology," published in I875. Parker's book, in sharp contrast to his previous "Zootomy," which is

NO. 147 I, VOL. 57] 